\title{
Search and Optimization of Factors to Improve Road Safety
}

\author{
Polina Aleksandrovna Buivol ${ }^{1}$, Gulnara Anvarovna Iakupova², Irina Viktorovna Makarova ${ }^{3}$, \\ Eduard Mukhamatzakievch Mukhametdinov ${ }^{4}$
}

${ }^{1}$ Candidate of Engineering, Associate Professor, Associate Professor of the Department of Transport Systems Service, Automotive Department, Naberezhnye Chelny Institute, KFU, ID Scopus: 57213147523,

ORCID: 0000-0002-5241-215X

${ }^{2}$ Senior lecturer of the Department of Transport Systems Service, Automotive Department, Naberezhnye Chelny Institute, KFU, ID Scopus: 257209369356, ORCID: 0000-0001-6822-3700

${ }^{3}$ Ph.D. Engineering, Head of the Department of Transport Systems Service, Automotive Department, Naberezhnye Chelny Institute, KFU, ID Scopus: 8901834700, ORCID: 0000-0002-6184-9900

${ }^{4}$ Candidate of Engineering, Associate Professor, Associate Professor of the Department of Transport Systems Service, Automotive Department, Naberezhnye Chelny Institute, KFU, ID Scopus: 56941836500 , ORCID: 0000-0003-0824-0001

\begin{abstract}
Accelerating urbanization leads to the emergence of megacities, which causes an increase in motorization of the population and the number of private and commercial vehicle fleets. Improving the quality of road infrastructure does not keep pace with the growth of the fleet of vehicles, which causes the emergence of problem situations in road safety. An effective measure to ensure the rational functioning of the urban transport system is the development and implementation of an intelligent road infrastructure management system, the intellectual core of which is simulation models of problem areas of the road network. It also requires a preliminary identification of factors affecting the likelihood of accidents and the severity of the consequences. As an example, the work describes the sequence of development and validation of decisions to optimize the city's transport system. For this, a simulation model has been developed for the selection of optimal parameters for the functioning of traffic lights on a specific section of the road network of the city of Elabuga.
\end{abstract}

Keywords: analysis of influencing factors, road safety, simulation, traffic light regulation.

\section{INTRODUCTION}

Accelerating urbanization leads to the emergence of megacities, which causes an increase in motorization of the population and the number of private and commercial vehicle fleets. Improving the quality of road infrastructure does not keep pace with the growth of the fleet of vehicles, which causes the emergence of problem situations in road safety. Although the statistics of road traffic accidents reflects the emerging trend of a decrease in the number of accidents, the situation remains tense due to the large total number of accidents and injured and killed people.

To reduce road traffic injuries, a number of infrastructural, information management, organizational and technical measures are proposed, including the widespread introduction of systems for automatic registration of traffic violations [1, 2], systems for collecting information about the situation on the roads [3, 4], protection the most vulnerable road users, pedestrians [5] and cyclists [6].

However, reducing the severity of the consequences on the roads as well as the number of injured needs firstly identifying the most significant factors affecting injuries in road accidents and developing methods for their smoothing.

\section{METHODS}

The authors of the work [7] consider traffic intensity as one of the most important factors influencing the number of road traffic accidents (RTA).

The authors of the study [8] identified the three most significant factors affecting the severity of the consequences of an RTA: the presence of a tunnel, the end or beginning of a divided highway, the presence of an intersection with a railroad bed at an intersection. The frequency of accidents at intersections is high, but they are unlikely to result in serious injury when compared to other critical road factors.

It is no coincidence that the authors of the work [9] chose city intersections for analysis as places that pose a serious safety threat, since most accidents within an urban area occur in places or near junctions. They analyzed the safety performance of the six types of intersections and the factors influencing the severity of accidents.

The work [10] investigates the issue of the severity of an accident in public transport. It was found that on weekends, at night, with poor road topography (curved, wet and uneven roads) and the absence of barrier separators of opposite traffic lanes, in collisions with pedestrians and drunk driving, the severity of the consequences is higher. Various types of collisions (with the exception of collisions with pedestrians) at 
International Journal of Engineering Research and Technology. ISSN 0974-3154, Volume 13, Number 11 (2020), pp. $3751-3756$

(C) International Research Publication House. https://dx.doi.org/10.37624/IJERT/13.11.2020.3751-3756

regulated intersections that do not have a shoulder are characterized as less traumatic.

The work [11] offers a method based on associative rules to analyze the characteristics and factors that contribute to the occurrence of accidents during road repairs. Most of the association's rules include conditions such as drunk driving, highways with more than 4 lanes, speed limits exceeding 40 $\mathrm{km} / \mathrm{h}$, and no traffic control devices.

Based on the analysis of the work, it can be concluded that the probability and severity of an accident is influenced by many factors, many of which become a reserve for improving road safety.

As a basis for the optimization of road traffic, many researchers consider the study of the existing road network in combination with a preliminary analysis of the available statistics of road accidents and highlighting significant factors [12-14], the study of traffic intensity at a specific object, its modeling and optimization of traffic lights, changing the number of lanes, erecting barriers and road signs based on the study [15-16].

Due to the limited budgets of medium and small cities, where there are also road safety problems, it is currently relevant to develop such measures that are not associated with a largescale reconstruction of street and road infrastructure, which requires large material costs.

\section{RESULTS AND DISCUSSION}

As the initial information for the analysis, we used open data collected by the State Traffic Safety Inspectorate in Elabuga for 2017-2018.

At the first stage, a classifier was built to determine the significance of factors using growing trees. As a result, after the construction of such trees for the objects of the road network, it was found that the most serious consequences occur in accidents at $\mathrm{T}$ and $\mathrm{X}$ shaped intersections without traffic light regulation: at unregulated intersections of unequal streets (roads), the average number of injured is 2; on railway tracks (where there are no objects at the accident site), exits from the adjacent territory, regulated pedestrian crossings 1.25 ; at regulated intersections, unregulated pedestrian crossings, public transport stops, unregulated roundabouts, inside courtyard territory - 1 .

Further, the places of concentration of RTAs with the largest number of injured in Elabuga were identified (Table 1).

Table 1: Distribution of the average number of injured by location

\begin{tabular}{|l|c|}
\hline \multicolumn{1}{|c|}{ Street } & $\begin{array}{c}\text { Average number of injured in } \\
\text { road traffic accidents }\end{array}$ \\
\hline $\begin{array}{l}\text { Molodezhnaya st., Okruzhnoe highway, Neftyanikov lane, Chapaeva st., Sh-2 st., } \\
\text { Marjaniul, Kazanskaya st., Proletarskaya st., Zemlyanukhina st., Gabdulla Tukaya } \\
\text { st., Bolgar st., Malaya Pokrovskaya st. }\end{array}$ & 1.000000 \\
\hline Neftyanikov avenue & 1.133333 \\
\hline Mira avenue & 1.125000 \\
\hline Moskovskaya street & 1.250000 \\
\hline Stroitelei street & 1.375000 \\
\hline Naberezhno-Chelninskoe highway & 2.000000 \\
\hline Tugarova street & 2.333333 \\
\hline Gassara street & 3.000000 \\
\hline
\end{tabular}

An analysis of the graphs of the average number of injured in the context of road infrastructure facilities showed that the most serious accidents in 2017 occurred at unregulated intersections of unequal roads, and in 2018 - also at regulated intersections, bridges and overpasses (Fig. 1). 


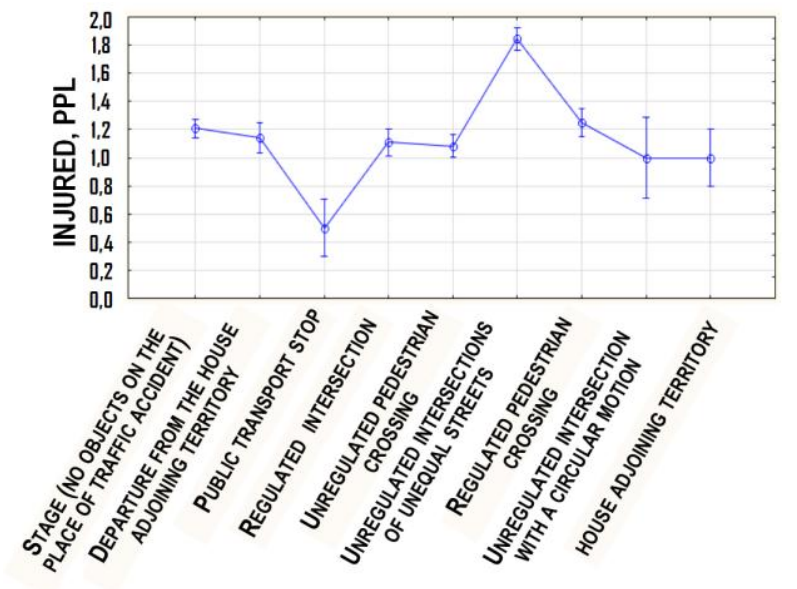

a

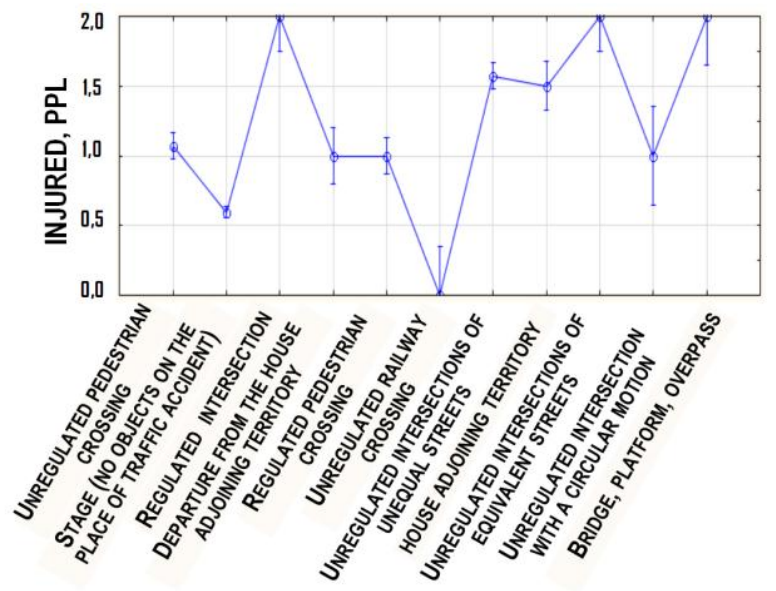

$\mathrm{b}$

Figure 1: Graphs of the average number of injured by road traffic police facilities: (a) 2017, (b) 2018.

To improve road safety, it is necessary to develop measures that eliminate traffic obstacles, leveling hazard factors and reducing the number of conflict situations that are created by existing road conditions. These activities include increasing visibility at the entrances to intersections, replacing unregulated intersections with self-regulating roundabouts, as well as traffic light regulation, construction of multi-level junctions and overpasses, organization of acceleration and deceleration lanes.

The analysis of the places of concentration of road accidents revealed the need to introduce regulation at the intersection of Neftyanikov Avenue with Okruzhnoye and Tanaevskoye highways in Elabuga to reduce the likelihood and severity of accidents.

As one of the solutions, we can offer the organization of a self-regulating ring intersection. The geometrical parameters of the road sections that require the construction of a circular intersection allow the implementation of this measure without hindrance with the corresponding diameter of the ring and island, as well as the width of the carriageway. The advantage of circular intersections is their ability to provide the safest and most comfortable traffic conditions at the intersection of roads, significantly reduce and eliminate conflict points of intersection of traffic flows, which in combination leads to a decrease in accidents and, especially, the severity of road accidents. It is also worth noting the low loss of time due to stops compared to regulated intersections. However, this type of intersection does not provide an effective organization of pedestrian traffic, therefore it is necessary to consider other measures aimed at increasing the safety of pedestrian traffic.

The solution to this situation can be the installation of a traffic light at this intersection, which with adequate adjustment can streamline traffic, reduce accidents by separating pedestrian and traffic flows, eliminate ambiguity in the interpretation of situations by drivers and ensure a safe crossing of the intersection by pedestrians and cyclists.

Additionally, organizing an adjustable pedestrian crossing and arranging pedestrian railings allows for the transfer of an unregulated pedestrian crossing near house 12 on Neftyanikov Avenue to this intersection, which will also increase safety in this area in terms of traffic management.

The effectiveness of this solution can be checked using simulation. The AnyLogic ${ }^{\circledR}$ software package was chosen as an environment for building a simulation model.

General parameters of road traffic in the city of Elabuga at a specific investigated intersection are presented in Table 2.

Table 2: Traffic parameters at the intersection of Neftyanikov Avenue, Okruzhnoye and Tanaevskoye Highways.

\begin{tabular}{|c|c|c|c|c|c|c|c|}
\hline No. & Street/road name & $\begin{array}{l}\text { Intensity, } \\
\text { units/h }\end{array}$ & $\begin{array}{l}\text { Intensity, } \\
\text { units/day }\end{array}$ & $\begin{array}{l}\text { Pedestrian } \\
\text { traffic }\end{array}$ & $\begin{array}{c}\text { Road capacity, } \\
\text { units } / \mathrm{h}\end{array}$ & $\begin{array}{l}\text { Traffic density, } \\
\text { vehicle } / \mathrm{km}\end{array}$ & Load factor \\
\hline 1 & Okruzhnoe highway & 1741 & 17,758 & low & 5000 & 43.53 & 0.35 \\
\hline 2 & Tanaevskoe highway & 258 & 2632 & low & 1800 & 5.16 & 0.14 \\
\hline 3 & Neftyanikov avenue & 1265 & 12,903 & moderate & 5000 & 28.11 & 0.25 \\
\hline
\end{tabular}

When running the model, the average duration of crossing the intersection was 33.39 seconds, which corresponds to field measurements (Fig. 2). Therefore, we can talk about the adequacy of the constructed model. 
International Journal of Engineering Research and Technology. ISSN 0974-3154, Volume 13, Number 11 (2020), pp. $3751-3756$

(C) International Research Publication House. https://dx.doi.org/10.37624/IJERT/13.11.2020.3751-3756

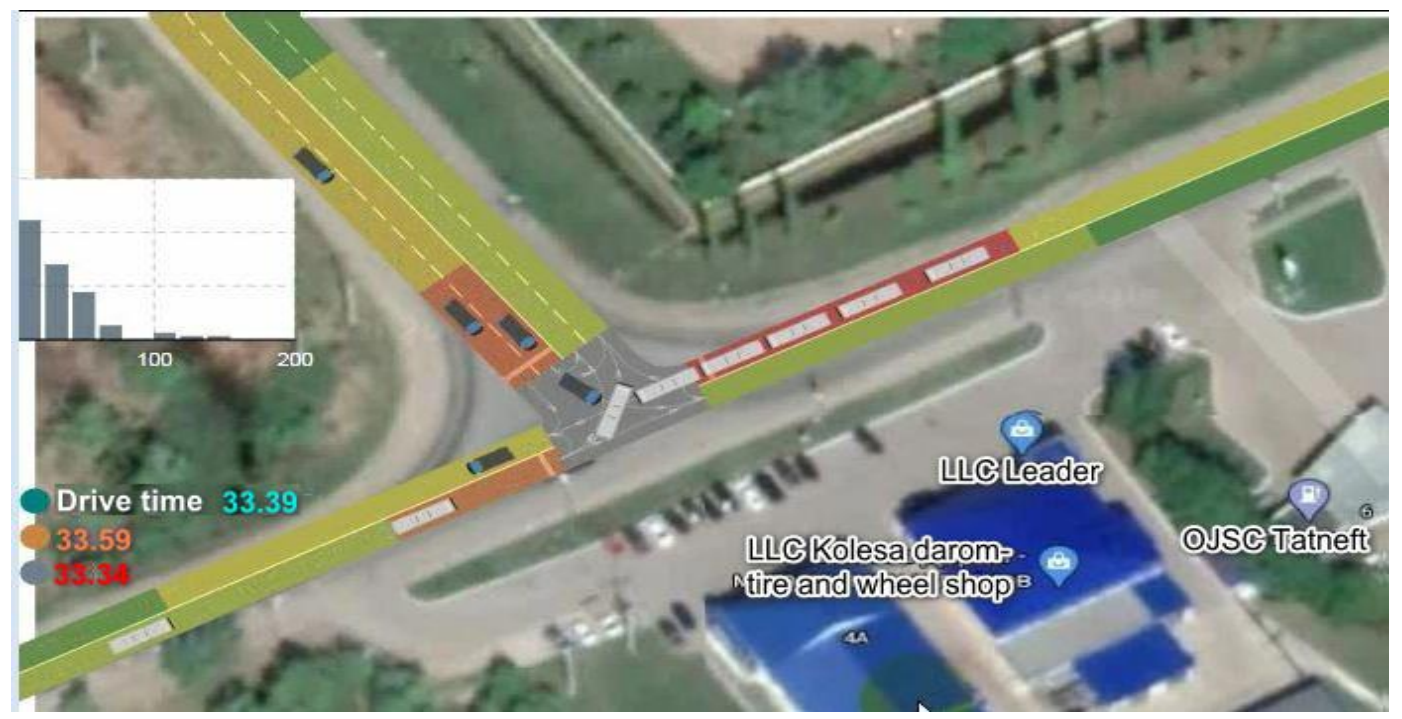

Figure 2: The results of the test of the intersection model with the current parameters without traffic lights

After that, an experiment was carried out with the addition of traffic light control with a three-phase cycle, i.e. for each direction of movement its own phase of crossing the intersection is highlighted. The found optimal solution showed the following result: the operating time of the green phase for Okruzhnoe Highway was 42 seconds, for
Neftyanikov Avenue - 50 seconds, for Tanaevskoe Highway 30 seconds. In this case, the average travel time of a road section by a vehicle was 40.82 seconds, which is $22 \%$ higher than when crossing this intersection without traffic light regulation (Fig. 3).
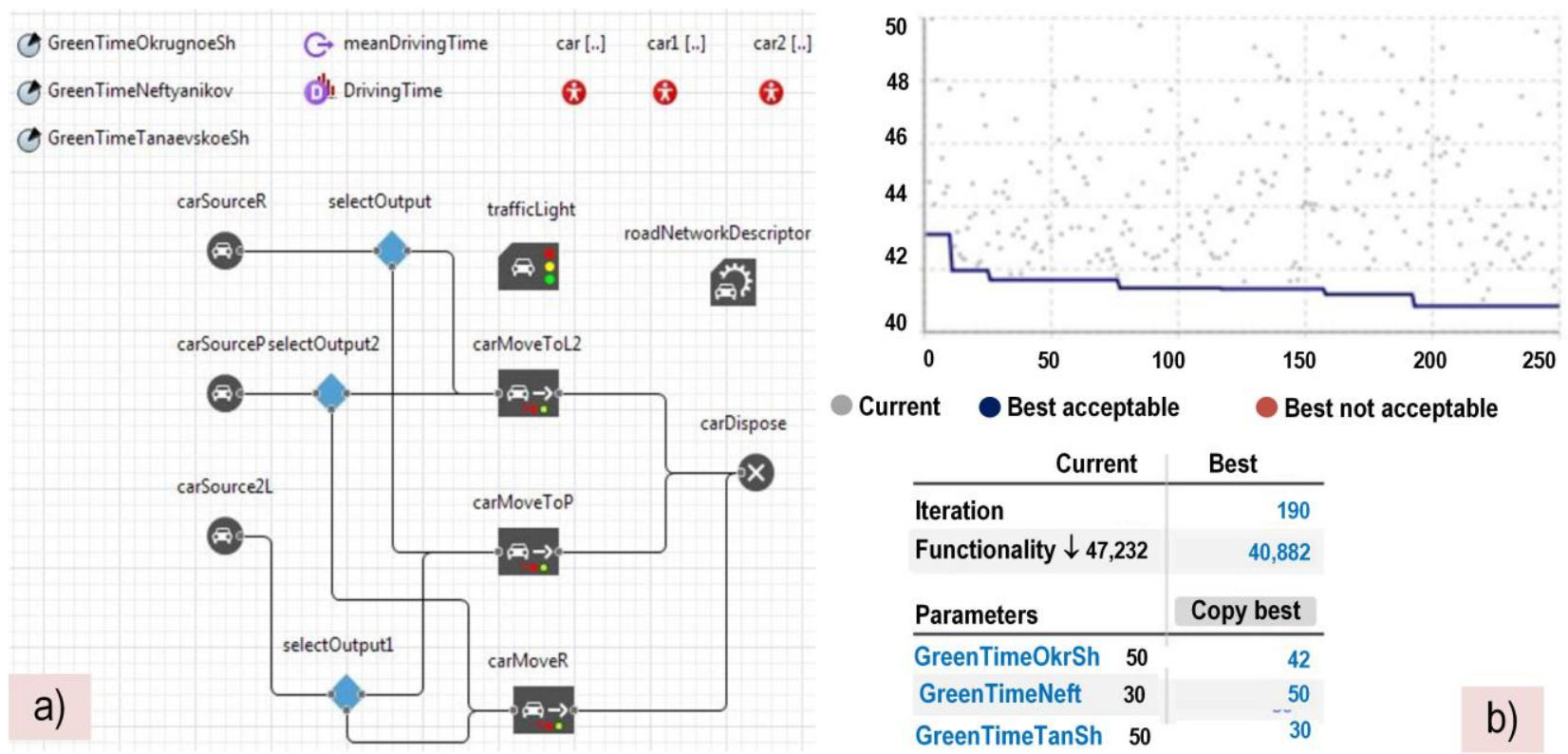

Figure 3: a) the structure of the IM crossroad of Elabuga; b) Results of the optimization experiment

Running the simulation model with the obtained optimal parameters for the three-phase control cycle shows a decrease in the traffic jams formed when crossing this intersection (Fig. 4). 


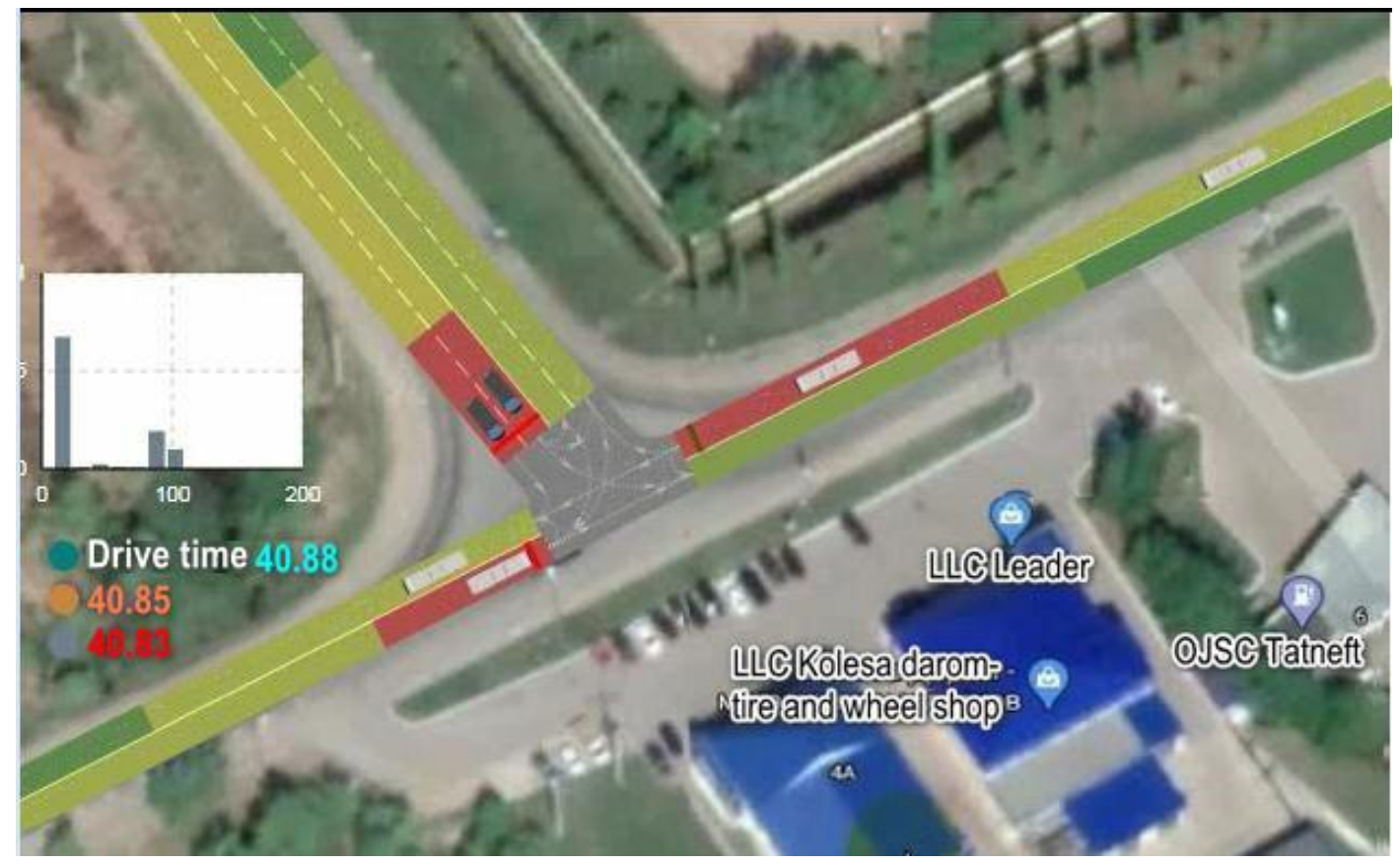

Figure 4: Results of running the intersection model with optimal parameters of the traffic light with a three-phase cycle

Considering the tasks put forward, we can talk about the effectiveness of the proposed solution, since, despite the fact that with a three-phase cycle of traffic lights, the time for a vehicle to cross this intersection increases, the number of conflict situations decreases, the likelihood of an accident is significantly reduced, and the severity of the consequences is presumably reduced.

\section{SUMMARY}

The article describes the sequence of development and validation of decisions to optimize the transport system of Elabuga. For this, a simulation model has been developed for selecting the optimal parameters for the functioning of traffic lights on a specific section of the road network. The practical significance of the model lies in the possibility of carrying out a series of experiments that make it possible to visually calculate the effect of installing a traffic light at a given intersection under various operating modes. The obtained values make it possible to talk about the possibility of reducing the number of conflict situations and improving road safety.

\section{CONCLUSIONS}

Accelerating urbanization leads to the emergence of megacities, which causes an increase in motorization of the population and the number of private and commercial vehicle fleets. Improving the quality of road infrastructure does not keep pace with the growth of the fleet of vehicles, which causes the emergence of problem situations in road safety.

An effective measure to ensure the rational functioning of the urban transport system is the development and implementation of an intelligent road infrastructure management system, the intellectual core of which is simulation models of problem areas of the road network. To facilitate the decision-making process, it is necessary to first identify the relationship between the consequences of road accidents and the factors that caused them, based on the analysis of available statistical data.

\section{ACKNOWLEDGMENTS}

The work is performed according to the Russian Government Program of Competitive Growth of Kazan Federal University. This work also was supported by the Russian Foundation for Basic Research: grant No. 19-29-06008\19.

\section{REFERENCES}

[1] Saha, S. Automated Traffic Law Enforcement System: A Feasibility Study for the Congested Cities of Developing Countries. In International Journal of Innovative Technology and Interdisciplinary Sciences, vol. 3, iss. 1, pp. 346-363, 2020. DOI: 10.15157/IJITIS.2020.3.1.346363.

[2] Agrahari, A., Singh, D. Smart City Transportation Technologies: Automatic No-Helmet Penalizing System. In: Singh D., Rajput N. (eds) Blockchain Technology for Smart Cities. Blockchain Technologies. Springer, Singapore, 2020. DOI: 10.1007/978-981-15-2205-5_6.

[3] Shepelev, V., Aliukov, S., Nikolskaya, K., Das, A. and Slobodin, I. The Use of Multi-Sensor Video Surveillance System to Assess the Capacity of the Road Network. In Transport and Telecommunication, vol. 21 (1), pp. 1531, 2020. 
[4] Shepelev, V., Glushkov, A., Almetova, Z. and Mavrin, V. A Study of the Travel Time of Intersections by Vehicles using Computer Vision. In Proceedings of the 6th International Conference on Vehicle Technology and Intelligent Transport Systems, pp. 653-658, 2020. DOI: 10.5220/0009806206530658.

[5] Tiwari, G. Progress in pedestrian safety research. International Journal of Injury Control and Safety Promotion, vol. 27, iss. 1, pp. 35-43, 2020, DOI: $10.1080 / 17457300.2020 .1720255$.

[6] K. Hosford, M.-S. Cloutier, M. Winters. Observational Study of Pedestrian and Cyclist Interactions at Intersections in Vancouver, BC and Montréal, QC. In Transportation Research Record, vol. 2674, iss. 6, pp. 410-419, DOI: 10.1177/0361198120919407

[7] M.Kh. Gatiiatullin. Intelligent transport system for large cities / M.Kh. Gatiiatullin, R.R. Zagidullin // Bulletin of the Scientific Center of Belarusian Railways. - 2010. No. 5. - P.76 - 82.

[8] Penmetsa, P., Pulugurtha, S.S. Modeling crash injury severity by road feature to improve safety. In Traf Inj Prev, vol. 19, iss. 1, pp. 102-109, 2018.

[9] Wu, P., Meng, X., Song, L., Zuo, W. Crash Risk Evaluation and Crash Severity Pattern Analysis for Different Types of Urban Junctions: Fault Tree Analysis and Association Rules Approaches. In Trans Res Rec, vol. 2673, iss. 1, pp. 403-416, 2019.

[10] Sam, E.F., Daniels, S., Brijs, K., Brijs, T. and Wets, G. Modelling public bus/minibus transport accident severity in Ghana. In Accident Analysis \& Prevention, vol. 119, pp. 114-121, 2018.

[11] Weng, J., Zhu, J.-Z., Yan, X., Liu, Z., 2016. Investigation of work zone crash casualty patterns using association rules. In Accident Analysis \& Prevention, vol.92, pp. 4352.

[12] Makarova, I., Yakupova, G., Buyvol, P., Shubenkova, K., Abeshev, K., Drakaki M. Improving Road Safety by Affecting Negative Factors. In Proceedings of the 5th International Conference on Vehicle Technology and Intelligent Transport Systems, vol. 1: LogiTrans 4.0, pp. 629-637, 2019.

[13] Yakupova, G.A., Buyvol, P.A., Mukhametdinov, E.M., Boyko, A.D. Road safety analysis from a viewpoint of influencing factors. In Proceedings - International Conference on the Developments in eSystems Engineering, DeSE 2019, pp. 806-811.

[14] Makarova, I., Yakupova, G., Buyvol, P., Mukhametdinov, E., Pashkevich, A. Association Rules to Identify Factors Affecting Risk and Severity of Road Accidents. In Proceedings of the 6th International Conference on Vehicle Technology and Intelligent Transport Systems (VEHITS 2020), pp. 614-621. DOI: $10.5220 / 0009836506140621$
[15] Makarova I., Shubenkova, K., Mavrin, V., Buyvol, P. Improving safety on the crosswalks with the use of fuzzy logic. In Transport Problems, vol. 13, iss. 1, pp. 97-109, 2018.

[16] Makarova, I., Yakupova, G., Buyvol, P. Improvement of the city transport system by means of simulation. In Revista Genero \& Direito, vol.8, iss. 6, pp. 239-248, 2019.

\section{About Authors:}

Polina Aleksandrovna Buivol. Candidate of Technical Sciences, Associate Professor, Associate Professor of the Department "Service of Transport Systems" of Naberezhnye Chelny Institute (branch), Kazan Federal University. 2012 successfully defended her thesis in specialty 05.13.01 System Analysis, Management and Information Processing. Lecturer of a course of lectures and laboratory and practical classes in "Intelligent control systems in the automotive industry", "Models and methods of decision support", "Information processing technologies". Research interests: system analysis and management of complex systems in the field of automotive service and transport.

Gulnara Anvarovna Iakupova. Teacher at Naberezhnye Chelny Institute, Kazan Federal University. Conducts lectures and practical classes in information systems and technologies, as well as mathematical subjects. At the same time, the author is actively involved in scientific mathematical and engineering research.

Irina Viktorovna Makarova. Ph.D. Engineering, Professor, Head of the Department of Transport Systems Service at Naberezhnye Chelny Institute (branch), Kazan Federal University. Honorary Worker of Higher Professional Education of the Russian Federation. Research interests: mathematical modeling of technical systems. Author of more than 400 scientific and scientific-methodical works, including 13 monographs, 110 Scopus articles and 63 Web of Science. Supervisor of 8 candidates of sciences.

Eduard Mukhamatzakievich Mukhametdinov. Candidate of Engineering, Associate Professor, Associate Professor of the Department of "Service of Transport Systems", Naberezhnye Chelny Institute (branch), Kazan Federal University. 2009 - successfully defended his thesis in specialty 05.22.10 - Operation of road transport "Improving the system of corporate service in order to increase the reliability of vehicles". Research interests: increasing the reliability in the operation of road transport. 